\title{
Significación social y territorio: aproximaciones metodológicas*
}

\section{Social signification and territory: methodological approximations}

Nelson Vergara Muñoz

Universidad de Los Lagos

Resumen: A partir de consideraciones teóricas relativas a los conceptos de territorio y de significación social, el trabajo se propone diseñar una metodología que permita identificar y comprender el carácter simbólico-imaginario de los proyectos territoriales, así como sentar las bases para la constitución de una Hermenéutica del Territorio, concebida como Hermenéutica Dialógica Territorial. La tarea principal de esta hermenéutica será descifrar sentidos del territorio a partir de narraciones y relatos de comunidades del sur patagónico de Chile. Se conjetura que en tales narraciones y relatos dialogarían interpretaciones contrapuestas, representativas del pensamiento oficial, tradicional todavía, y pensamientos contestatarios en los que se puede vislumbrar la aparición de actitudes hermenéuticas antitradicionales. La proyección, desarrollo y formalización de estas nuevas actitudes interpretativas serán el fundamento de la propuesta de una efectiva Hermenéutica Dialógica Territorial.

Palabras clave: Territorio. Territorialidad. Dialógica. Significación social imaginaria.

\begin{abstract}
Starting from theoretical considerations related to the concepts of territory and social signification, this paper proposes the development a methodology that allows for the identification and comprehension of the symbolic-imaginary nature of territorial projects, as well as establishing the basis for the construction of a Hermeneutics of Territory, conceived as Dialogic Territorial Hermeneutics. The main goal of this hermeneutics will be to decipher the meanings of the territory as presented in narrations and stories from communities of the southern Patagonian region of Chile. It is believed that such narrations and stories would communicate conflicting interpretations, representing both the official thinking, which is still traditional, and the dissenting thoughts in which the emergence of non-traditional hermeneutic attitudes can be seen. The projection, development and formalization of these new interpretative attitudes will be the foundation for the proposal of an effective Dialogic Territorial Hermeneutics.
\end{abstract}

Keywords: Territory. Territoriality. Dialogic. Imaginary social signification

* Este artículo es el desarrollo de la presentación que hiciera en julio de 2011 en la Universidad Estatal de Ponta Grossa con motivo del congreso de investigadores de faxinais. El texto y la ponencia son producto del proyecto de investigación interdisciplinaria denominado "Discursos e Identidades Territoriales: estudios literarios, patrimoniales y culturales", realizado bajo la modalidad de Núcleos de investigación y financiado por la Vicerrectoría de Investigación y Postgrado de la Universidad de Los Lagos, para los años 2011-2012. 


\section{INTRODUCCIÓN: OBJETIVOS}

Desde hace algún tiempo, el interés que nos motiva, pasa por dilucidar la consistencia del territorio ${ }^{1}$. En esta tarea, consideramos el territorio como parte esencial de la condición humana, en el sentido de que no es simplemente un entorno que se suma al proyecto de hábitat, como algo que simplemente está ahí y que puede ser hallado en forma independiente del proyecto y provisto de autonomía. Por esto hemos iniciado una exploración del tema territorial desde su condición social-significativa; más concretamente, y siguiendo a C. Castoriadis (2005; 2007), como una significación social imaginaria. Por tanto, para nosotros, el territorio y, consecuentemente la territorialidad, no es un elemento objetivo en el sentido materialista del término, ni subjetivo en el sentido idealista, sino algo que, posicionándose significativamente de un entorno siempre calificado, heterogéneo y diverso, en que lo humano sucede como realidad histórico-social y no natural, emerge creativamente desde la subjetividad de la experiencia colectiva, experiencia en que sociedades y comunidades se reconocen en una relación que podemos llamar condición de territorialidad, que les permite representarse unas respecto de otras y de sí mismas, es decir identificarse $\mathrm{y}$ diferenciarse a la vez.

\section{SUPUESTOS BÁSICOS}

Pero esto tiene varios alcances que funcionan como supuestos y que delimitan el horizonte en que nos movemos.

Uno de ellos afirma que el territorio senos aparece como un proyecto sociohistórico, por ejemplo, una sociedad, una comunidad,

\footnotetext{
${ }^{1}$ Ver, especialmente, "Hombres y entornos", "Complejidad, espacio, tiempo e interpretación", "Saberes y entornos" (VERGARA MUNHOZ, 2007; 2009; 2010).
}

un grupo humano; con otras palabras, un sistema institucional (CASTORIADIS, 2007), si bien se constituye como lo otro del proyecto, como aquello a lo que el proyecto tiende, se siente sin embargo como parte integrante de él, aun cuando muchas veces parezcan incoherentes, $\mathrm{o}$ en abierta oposición y antagonismo ${ }^{2}$. El territorio no es, por lo tanto, síntoma de armonías, adecuaciones plenas o relaciones perfectamente ordenadas a los objetivos del proyecto de vida en común, sino que, muchas veces, es esa suerte de contra voluntad con que suele manifestarse toda circunstancia, sea favorable o sea adversa, pero que se revela más nítidamente en este segundo caso (ORTEGA y GASSET, 1964). De este modo entendemos que el territorio cobra realidad material en las circunstancias, lo que implica que, por principio, no es algo material. Es decir que el territorio no está simplemente afuera como no puede estarlo una cosa o una persona, objetivamente, a la manera planteada por el realismo tradicional y moderno.

Pero esto no puede confundirnos: el territorio tampoco es un producto ideal, una idea o un concepto como lo ha propuesto la interpretación idealista. Por esto, cuando decimos que el territorio es una proyección subjetiva, imaginaria, suponemos, en segundo lugar, el territorio como algo generado por el proyecto en vistas de las circunstancias, como un mundo o mundos que hay que alcanzar, como una suerte de utopía a la que hay que llegar y que surge cargada de intenciones y deseos humanos de posesión. Por esto es que puede decirse que el territorio es espacio apropiado, hecho propio, un espacio de identidad y de historia ${ }^{3}$, cuya consistencia fundamental es

\footnotetext{
${ }^{2}$ Queremos decir que esta situación puede incluso llegar a hacer sentir la institución como extraña o ajena y, como tal, fuente de alienación cuando se autonomiza demasiado.

3 Confróntese las ideas de M. Augé y Gilberto Giménez
} 
ser un sistema de significaciones y como tal un sistema de interpretación ${ }^{4}$. Esta condición esencial puede observarse claramente en los gestos fundacionales de descubridores o conquistadores, conocidos como toma de posesión. Pero no solamente en estos casos heroicos, sino también en las muy habituales tomas de terrenos con que comunidades carenciadas suelen instalarse en espacios no habitados de ciudades y campos. Por ejemplo, terrenos baldíos, casas deshabitadas, etc. ${ }^{5}$

Un tercer asunto que nos compete y que también juega al modo de un supuesto, es que el territorio no es una simple consecuencia, un producto generado o emanado mecánicamente por la subjetividad individual, sino que, siendo una creación imaginaria se constituye como un producto del diálogo (MORIN, 2003) entre un proyecto colectivo de vida en común y el entorno sociohistórico en que se instituye; allí se hace realidad en virtud de acciones e interacciones de significación pragmáticas y de tomas de posesión significativas, por ejemplo, de tomas de la palabra ${ }^{6}$. En este diálogo, el proyecto y el entorno aparecen tanto antagónicos como complementarios, precisamente por el acto de reconocimiento; lo que introduce en la relación un factor de recursividad (MORIN, 2003) en que uno es lo que es en razón del otro y viceversa. Así, el proyecto hace al territorio como éste hace a aquél. Por lo tanto, no hay proyecto sociohistórico sin territorio, ni territorio en abstracto, autónomo e independiente de lo social histórico, aun cuando en ciertos momentos no sean sino partes de un mismo sueño

\footnotetext{
${ }^{4}$ Confróntese la relación de realidad e interpretación en P. Ricoeur y J. Ortega

${ }^{5}$ Quizás por esto convendría pensar la utopía como perteneciendo tanto al pasado como al futuro, es decir, como lo que se arrastra o lleva a cuestas.

${ }^{6}$ Con otras palabras, que el proyecto territorial no surge de la nada, de una ausencia de significaciones o interpretaciones, ni en su origen ni en su decurso histórico, sino que viene ya cargado de expectativas convocantes.
}

colectivo. Su materialización, sin embargo, exige la presencia y la realidad concreta de ambos: del proyecto colectivo y del espacio apropiado.

Un cuarto supuesto, que nos parece decisivo, es que esta condición dialógica y recursiva de la territorialidad y la significación social no debe considerarse de efectos homogéneos y unívocos, creadora de relaciones armónicas y simples, sino más bien como la expresión de una complejidad en que un proyecto sociohistórico se enfrenta a otros proyectos de la misma índole, a quienes puede someter temporalmente, circunstancialmente, y que pueden volver a ser significativos, recuperando su importancia para la sociedad o resignificándose para una parte de ella, por lo que normalmente plantea necesidades de reivindicación, al menos a nivel de la memoria histórica. El territorio es entonces producto también de estas resignificaciones sociales imaginarias. Allí, un sentido dialoga con otros sentidos, por ejemplo tradicionales, los que entonces tienden a ser reemplazados con variadas suertes y destinos. Esto muestra que el territorio jamás es efectivamente una realidad monolítica y estática, sino una invención sujeta a variaciones constantes, a cambios a veces radicales, o sea una realidad compleja y dinámica ${ }^{7}$.

La institución social imaginaria de un nuevo sentido del territorio pasa entonces por momentos que se ofrecen no tanto en el orden de las sucesiones como en el orden de las profundizaciones, al modo de las formaciones geológicas, en las que se van depositando las significaciones, formando capas arqueológicas de significados operantes, aunque casi nunca plenamente conscientes. Son significaciones que

\footnotetext{
${ }^{7}$ Podemos reconocer aquí uno de los caracteres esenciales que Raúl Fornet-Betancourt, en su postulada Filosofía Intercultural, atribuye a la cultura en general: ser producto no solamente de tensiones hacia el exterior de ella, sino también de tensiones y conflictos internos.
} 
más parecen vivirse que pensarse y que para alcanzarlas nos resulta necesario el concurso de una hermenéutica que vaya tras esas profundidades, hasta llegar a lo que pueda estimarse como el nivel de mayor hondura, sitio en que normalmente ocurre la dilución de lo racional y lógico de lo inmediato, en lo imperfecto y abismático. Este acontecimiento constituye entonces al proyecto en un trayecto, en un acontecer cuya consistencia espacio-temporal es un pasar significativo de lo superficial a lo profundo y viceversa, instalando así lo que podemos comprender como un quinto supuesto: el de la necesaria interpretatividad del territorio, sedimentada en significaciones dinámicas y que justifican en definitiva a los intentos hermenéuticos que estamos postulando.

\section{Territorio e institucionalidad}

En la atención prestada a estas etapas semánticas, cabe distinguir lo que Castoriadis (2007) reconoce como el camino de una institución social imaginaria, de lo que el territorio representa una de las más importantes y decisivas. En esta institución vemos la dialogicidad y recursividad moriniana en por lo menos tres etapas semánticas: la de la funcionalidad, la del simbolismo y ritualidad ${ }^{8}$, y la de lo imaginario; interacciones cuya clarificación nos parece que puede aportar luces para comprender el sentido o los sentidos del territorio y de esa condición sociohistórica que es nombrada con el término de 'territorialidad'. En lo esencial sostenemos, con Castoriadis, que tanto la funcionalidad como el simbolismo y su ritualidad, así como también lo imaginario, siendo imprescindibles, no son, suficientes por sí mismos, como si

${ }^{8}$ Agregamos aquí la idea de ritual porque nos parece que como práctica social es inseparable del simbolismo como interpretación. fuesen sin más dados, lo que obliga a considerarlos como dimensiones del proceso de creación o invención de la vida social e histórica. En una breve síntesis dice Castoriadis que siempre acostumbramos a relacionar lo funcional con la satisfacción más inmediata y directa de necesidades como si éstas fuesen, en rigor, naturales. Pero lo funcional ha de plantearse siempre con relación a algo que nunca se presenta así; de modo que debemos entender que las necesidades están siempre condicionadas social y culturalmente, del mismo modo que lo están los fines o valores. De esta manera, a su juicio, es la propia funcionalidad la que queda enmarcada y sometida a "puntos de vista, orientaciones, cadenas de significaciones que la condiciona" (2007, p. 219). Esto quiere decir que toda funcionalidad social actúa entonces en un marco que la configura: y esto es siempre una red simbólica que, como tal y por principio, no puede remitir a sí misma, ni explicarse a sí misma, lo que se revela en el hecho de que siempre puede suscitar preguntas que el simbolismo (y ritualismo) no puede responder. Por ejemplo, ¿por qué una comunidad o sociedad histórica elige un determinado sistema de símbolos (y rituales) que le son característicos? ¿qué significaciones son difundidas por esos sistemas de símbolos (y rituales)?

En definitiva, Castoriadis concluye que:

La funcionalidad toma prestado su sentido fuera de ella misma; el simbolismo se refiere necesariamente a algo que no está entre lo simbólico, y que tampoco está entre lo real-racional. Este elemento que da a la funcionalidad de cada sistema institucional su orientación específica, que sobredetermina la elección y las conexiones de las redes simbólicas, creación de cada época histórica, su manera singular de vivir, de ver y de hacer su propia existencia, su mundo y sus propias relaciones; este estructurante originario, este significadosignificante central, fuente de lo que se 
da cada vez como sentido indiscutible e indiscutido, soporte de las articulaciones y de las distinciones de lo que importa y de lo que no importa, origen del exceso de ser de los objetos de inversión práctica, afectiva e intelectual, individuales y colectivos -este elemento no es otra cosa que lo imaginario de la sociedad o de la época considerada (2007, p. 234).

Lo imaginario es entonces esa fuente de la que emergen las significaciones sociales que están en la base más profunda de la red de instituciones que forman la sociedad, lo que estimamos que se da a nivel de las sensibilidades, sin forma específica, pero que son susceptibles de adquirirla en virtud de símbolos y rituales sui generis para cada formación sociohistórica y que eventualmente conduce a que algunas de esas significaciones se vuelvan relativamente funcionales en un cierto sentido. De este modo podemos argumentar que hay una recursividad estrecha entre sentidos (imaginarios), símbolos y rituales que una comunidad selecciona en el trayecto de su proyecto de vida. La funcionalidad, sin embargo, parece actuar un tanto más aleatoriamente ya que siempre es posible encontrar significaciones sociales que no cumplen ningún papel funcional, más bien parecen contradecirlo. No tanto así el simbolismo. Y menos aún lo imaginario. Por esto lo funcional es removible más fácilmente que las otras dos etapas ${ }^{9}$.

\section{Para una interpretación adecuada}

Si estos son aspectos, o supuestos, que no podemos eludir a medida que el territorio y la propia territorialidad se nos aparece

\footnotetext{
${ }^{9}$ En un texto anterior decíamos refiriéndonos a la que nos parece ser la condición más propia del territorio que este era una realidad más que nada imaginaria. Lo anterior puede servir de fundamento a esa tesis. Confróntese "Saberes y entornos" (VERGARA MUNHOZ, 20010).
}

como expresiones de significaciones sociales imaginarias, y si el territorio es propiamente una realidad que se lleva adentro y no un hecho efectivo encontrable afuera del proyecto humano de que se trate, entonces podemos preguntarnos, ¿cómo debemos entenderlo?, ¿cómo nos hacemos cargo de ello?

Dos cuestiones nos parecen relevantes en este sentido: la primera es que el territorio como significación social imaginario ha de aparecernos en significados específicos y la segunda, que cualquier metodología que pretenda dar cuenta de tales significaciones tiene que tomar en cuenta la especificidad de esas características. Ahora proponemos dilucidar las significaciones en qué consiste el territorio en significantes que se presentan como narraciones y relatos y para hacerlo estimamos que una metodología apropiada es la confrontación de esas narraciones y relatos en el marco de interacciones dialógicas.

Para el primer caso seleccionamos, por un lado, narraciones y relatos, discursos, en que se despliegan significaciones oficiales, representativas de la autoridad de organismos que de algún modo autoritario están relacionados con el ordenamiento estatal o nacional, tales como documentos que manifiestan una racionalidad global, científica, objetiva en el sentido más clásico del término, y por otro lado aquellos discursos que pueden considerarse contestatarios, sean intelectuales o artísticos, pero que son representativos de grupos humanos que se distinguen por su especificidad local o localizable en sectores de la vida colectiva, y que pretenden hacerse oír como voces válidas. El diálogo de estos tipos de discursos puede ser una buena manera de apropiarse de esas emociones, percepciones, representaciones, opiniones, creencias y sensibilidades en que se despliegan sentidos contrapuestos de 
territorios, que muestran, de esta manera, su fuerte filiación semántica, ya que hunden sus raíces en imaginarios sociales de mayor o menor envergadura. A continuación relatamos algunos alcances que, en estas indagaciones, estamos proponiendo como metodología de lo que hemos denominado una Hermenéutica Dialógica Territorial, fuertemente arraigada para descifrar sentidos del territorio en narraciones y relatos de comunidades del sur-patagónico de Chile.

\section{Para una metodología dialógica}

Para diseñar, construir y poner en práctica un modelo teórico-hermenéutico que nos permita comprender la complejidad de los proyectos territoriales, desplegados arqueológicamente, se propone entonces una estrategia que contempla tres etapas:

I: elaboración de un corpus discursivo de base teórica en el que se describen y justifican ideológicamente, los contrastes fundamentales entre discursos teóricos tradicionales, monológicos y reduccionistas, sostenidos por el paradigma de la simplicidad y discursos teóricos, sustentados por el paradigma de la complejidad, de acuerdo a los conceptos desarrollados por E. Morin (2003);

II: identificación y estudio de prácticas discursivas preparados como narraciones y relatos, oficiales y extraoficiales, para probar la trascendencia teórica y la superioridad de la perspectiva dialógica en el conocimiento de los proyectos territoriales de la vida cotidiana, tarea en que deberán reconocerse la presencia y el valor de los imaginarios como claves de la construcción social de los espacios territoriales, en primer lugar, espacios de la macroregión Sur-Austral de Chile;

III: construcción formal, sistematización $\mathrm{y}$, eventualmente, puesta en práctica de un modelo interpretativo territorial concebido como Hermenéutica Dialógica Territorial, que pueda ser aplicable también a territorios de otras regiones.

\section{Etapa I: Construcción del Corpus Discursivo}

Luego de identificar la condición lingüístico-semiológica de entradas teóricas seleccionadas (Teoría de la Cotidianidad, Teoría de la Complejidad, Teoría de Imaginarios, Filosofía Intercultural, Pensamiento Ambiental) esta etapa se propone, en primer término poner en diálogo esas teorías y sus eventuales prácticas correlacionadas, con aquellas teorías, preferentemente de orden positivista, contrastando sus caracteres en distintos niveles y tipos de instancias, lo que supone, un trabajo sistemático y en profundidad para ordenar y aclarar tanto las fuentes como los conceptos fundamentales implicados en ellas, ya sean tradicionales, monológicas, como las positivistas, ya sean antitradicionales, dialógicas, como las señaladas al comienzo de este párrafo. Esto exigirá una reflexión individual y colectiva de gabinete que, considerando las tensiones sociales básicas, destacadas y aborde lo dialógico en varios planos, principalmente:

a) entre teorías y prácticas teóricointerpretativas y territoriales tradicionales y antitradicionales,

b) entre actores oficiales y extraoficiales (del Estado y de la Sociedad Civil),

c) entre interpretaciones vividas e interpretaciones razonadas, planificadas,

d) entre imágenes (ideologías, utopías) intelectuales y artístico-artesanales, generadas en las vivencias de la territorialidad, por un lado, y las imágenes político-económicas, educacionales (ideologías, utopías), oficiales de los organismos de la Nación o el Estado, por otro; 
e) entre disciplinas naturales y disciplinas sociales y humanas.

Así, la tarea de interpretación se concebirá como "entrar en diálogo" con el complejo armazón social de la realidad sociohistórica (espacios efectivos, espacios imaginados, vida cotidiana). Esta estrategia nos permitirá confrontar conceptos y vivencias en las textualidades teóricas comprometidas en la investigación como entradas teóricas, que son la fuente de la investigación en esta etapa y, además, evaluar su impacto en el debate actual de las interpretaciones.

Paralelamente, se construirán cartografías, conteniendo información documental territorial (narrativas y relatos oficiales y extraoficiales), las que se trabajarán según los enfoques confrontados acorde a la dinámica de los diálogos propuestos para el estudio de la apropiación del espacio, de la construcción social del espacio, de la noción de proximidad y lejanía, de fronteras y bordes, y representaciones e imágenes (ideologías y utopías) de los distintos actores, entre otros. El objetivo de esta cartografía será el registro y preservación de fuentes que en la segunda etapa servirán para el estudio sistemático de la interpretación de los espacios escogidos como representativos del territorio, principalmente aquellos rurales y urbanos que en la actualidad se manifiestan en términos de conflictos.

\section{Etapa II: Estudio sistemático de Narraciones y Relatos como registro de Prácticas discursivas cotidianas}

Para el cumplimiento de esta segunda etapa, se identificarán, describirán y categorizarán las prácticas discursivas cotidianas ${ }^{10}$ producto de las cartografías

${ }^{10}$ Esta noción tiene deudas importantes con la teoría de la vida cotidiana del filósofo chileno Humberto Giannini (1987). obtenidas en la Etapa I, para relacionarlas interpretativamente con las teorizaciones obtenidas en el primer año. En esta tarea, se pondrá en acción un plan de contrastación y corroboración de las teorizaciones interpretativas dialógicas obtenidas, lo que implicará una puesta a prueba de las teorías, según lo conjeturado en los objetivos e hipótesis de esta investigación ${ }^{11}$. El trabajo abordará los significados y reglas de significación, que circulan o se comparten en las redes intersubjetivas de las entradas teóricas, las narraciones y relatos recopilados; así como las actividades asociadas a técnicas de lectura crítica (Hermenéutica, Análisis Crítico del Discurso, Crítica de Ideologías), con el fin de:

a) leer los documentos recopilados, a la luz de una dialógica en construcción, para identificar y registrar las distintas dinámicas sociales y culturales que en ellos caracterizan a los espacios seleccionados. Como producto se espera contar con una matriz de caracterización que configura a los espacios territoriales;

b) revisión bibliográfica y documental; se trata de la indagación, en fuentes documentales, de la caracterización esencial de los espacios, como por ejemplo: planos, documentos históricos que se refieran a ellos, bases de datos, cuerpos legales en general, instrumentos de planificación, planes de intervención, fundamentalmente Estrategias de Desarrollo Regional y Planes de Desarrollo Comunales, entre otras fuentes, que narren o relaten las perspectivas institucionales de los últimos 35 años, así como narraciones y relatos de escritores, artesanos y otros documentos no gubernamentales, representativos de las perspectivas no gubernamentales de la región Sur-Austral en las mismas fechas;

\footnotetext{
${ }^{11}$ Para la formulación y contrastación empírica de estas conjeturas, nos sustentamos en la teoría epistemológica y metodológica de Karl Popper (1992).
} 
todo esto, con el fin de contextualizar las especificidades que han dado sustento a las dinámicas y tensiones culturales de estos lugares en los tiempos señalados;

c) registrar representaciones e imágenes, con la finalidad de tener una percepción visual de los cambios y dinámicas producidas en el tiempo señalado. En definitiva, esto constituirá la fuente de aplicación inmediata y de gabinete de la Hermenéutica Dialógica propuesta, así como su mecanismo de revisión y corrección.

Como resultado de lo anterior estimamos que se obtendrán mapas temáticos de la percepción de los habitantes respecto a su entorno, lo que permitirá trabajar, abordando aspectos como representaciones e ideologías de división social y división funcional del espacio y aspectos de cultura regional. Para esto, se revisarán y contrastarán metodologías y enfoques de la geografía de la cotidianidad con la arqueología de la cotidianidad (GIANNINI, 1987), supuestamente inmersos e implicados en las narrativas y relatos seleccionados y cartografiados. La estrategia es avanzar al encuentro de esas significaciones sociales imaginarias para comprenderlas en su profundidad o arqueología. Esta estrategia será abordada tomando en cuenta aspectos tales como:

a) comprensión de las técnicas que ponen en juego a los transeúntes, intelectuales, artistas (principalmente escritores y artesanos) y funcionarios oficiales, sobre cómo hacer las cosas;

b) comprensión de las interpretaciones de la realidad de los transeúntes. Desde este punto de vista nos acercaremos a la comprensión de las vivencias que las personas tienen de los espacios territoriales por los que cotidianamente transitan. Para esto se pondrá de relieve la coherencia teórico-práctica entre las teorías interpretativas que se irán construyendo como alternativas a las tradicionales hermenéuticas monológicas, reduccionistas, que son propias de la manera oficial de comprenderlos y de sus prácticas de apropiación sociocultural de los espacios, tal como podemos observar en sus documentos esenciales (planes, programas de desarrollo cultural, político y educativos) en los que se sostienen principalmente las oficinas gubernamentales.

\section{Etapa III: Creación de una propuesta de Modelo interpretativo territorial}

Esta tercera etapa establecerá los fundamentos teóricos y prácticos de la nueva hermenéutica, y desarrollará los principios epistemológicos y metodológicos de un modelo hermenéutico dialógico original, que se constituirá como base de un Programa de Investigación Territorial, proyectable al estudio de espacios que puedan trascender las regiones sur australes y acceder al estudio territorial de otras regiones de Chile y Latinoamérica, siempre en el contexto de las prácticas o experiencias cotidianas de apropiaciones socioculturales de los territorios.

Como se ha reiterado, la idea es que el modelo supere la unilateralidad que supone el uso de las metodologías hermenéuticas modernas, cuyos principios fundamentales reseñamos como la monodisciplinariedad, la reductibilidad de niveles y ámbitos de investigación más simple, la constitución de lo real como datos elementales, la separación neta de ámbitos como los naturales y socioculturales, de lo científico y lo tradicional, la eliminación de factores subjetivos en la interpretación, etc., es decir, todo aquello que por lo general identifica a las teorías y prácticas cientificistas del positivismo. De este modo, las actividades se formalizan así: 
a) trabajo de gabinete para el grupo de investigación en el que se revisarán experiencias y bibliografías que permitan la formalización, sistematización y el desarrollo de la Teoría Hermenéutica Dialógica Territorial que identifique al grupo de investigación;

b) modelización de las interpretaciones, identificando divergencias y convergencias entre ellas y los objetos en estudio;

c) discusión del modelo deinterpretación, reconociendo eventuales necesidades de ajuste.

Lo central es que esta etapa formalice las matrices de un modelo hermenéutico para el estudio de los territorios.

En definitiva, esta etapa se propone construir un modelo hermenéutico que, trascienda su condición tradicional moderna, se engrandezca en la complejidad de la experiencia cotidiana territorial, y escrudiñe los secretos culturales (imaginarios) que operan latentes en ella (creencias, supuestos, intereses, inconsciencia, ideologías, utopías, mitos, etc.).

Pero es claro también que este modelo no escapará a su historicidad, lo que implica una constante puesta en valor de los conceptos, categorías y principios fundamentales, consciente de que nunca se puede alcanzar una comprensión total y definitiva (GADAMER, 1993; POPPER, 1992), partiendo y concluyendo en la tesis que afirma que nuestro tiempo puede caracterizarse por la creciente preeminencia de la cultura en los mundos del futuro (SUBERCASEAUX, 1991; GARRETÓN, 2000).

\section{REFLEXIONES DE CIERRE}

Considerando que toda reflexión se encuentra siempre entre dos polos provisionales que se identifican como aquello de lo que se parte y aquello a lo que se tiende, nos parece importante referir lo pertinente a esta situación fundamental en la constitución de una teoría:

- en primer lugar, señalar que esta propuesta hermenéutica quiere recoger lo mejor de las hermenéuticas contemporáneas que asumen la territorialidad como una condición irrenunciable, aunque polémica y que quiere aproximarse a ella mediante el fruto de nuestra tradición filosófica que no es independiente de la democracia. De aquí el valor atribuido al diálogo y la participación de las prácticas cotidianas discursivas;

- en segundo lugar, indicar que la tarea hermenéutica no se detiene aquí, que la Hermenéutica Dialógica Territorial en construcción es una parte importante de un proyecto mayor que deberá abordar también problemas del Tiempo y del lenguaje que aquí están supuestos por su preferencia por cuestiones espaciales. De este modo, nos parece pertinente anunciar que tal Hermenéutica Dialógica Territorial deberá integrarse en una hermenéutica del tiempo y que ambas deberán formar parte de una necesaria y genuina Hermenéutica Dialógica Ambiental que nuestro tiempo necesita con urgencia cada vez mayor. Al respecto nos parece que reflexiones como las de E. Leff, M. Santos, A. Escobar, D. Floriani, R. Fornet-Betancourt, W. Mignolo, entre otros latinoamericanos, están abriendo los caminos que corresponde abrir.

\section{REFERENCIA}

CASTORIADIS, Cornelius. La institución imaginaria de la sociedad. Buenos Aires: Tusquets ediciones, 2007.

CASTORIADIS, Cornelius. Los dominios del hombre. Barcelona: Editorial Gedisa, 2005.

GADAMER, Hans Georg. El problema de la conciencia histórica. Madrid: Editorial Tecnos, 1993. 
Nelson Vergara Muñoz

GARRETON, Manuel Antonio. La sociedad que vivi(re)mos. Stgo de Chile: LOM editores, 2000.

GIANNINI, Humberto. La "reflexión" cotidiana. Stgo de Chile: Editorial Universitaria, 1987.

MORIN, Edgar. Introducción al pensamiento complejo. Barcelona: Editorial Gedisa, 2003.

ORTEGA Y GASSET, José. El hombre y la gente. Madrid: Revista de Occidente, Col. El Arquero, Tomos I y II, 1964.

POPPER, Karl. Conocimiento objetivo. Madrid: Editorial Tecnos, 1992.

SUBERCASEAUX, Bernardo. Historia, literatura y sociedad. Ensayos de hermenéutica cultural. Stgo de Chile: Documentas/CENECA/ CESOC, 1991.

VERGARA MUÑOZ, Nelson. Hombres y entornos. Notas para una metafísica del territorio. Alpha, n. 25, 2007, Universidad d Los lagos, p.227-236.

Complejidad, espacio, tiempo e interpretación. Notas para una hermenéutica del territorio. Alpha, n. 28, 2009, Universidad de Los Lagos, p. 233-244.

Saberes y entornos. Notas para una epistemología del territorio. Alpha, n. 31, 2010, Universidad de Los Lagos, p. 163-174.

Recebido em: 27/09/11

Aceito em: 06/11/11 